\title{
Development of a novel anti-human aspartyl-(asparaginyl) $\beta$-hydroxylase monoclonal antibody with diagnostic and therapeutic potential
}

TING HUYAN* ${ }^{*}$ QI LI* ${ }^{*}$ DAN-DAN DONG, HUI YANG, XIAO-PING XUE and QING-SHENG HUANG

Key Laboratory for Space Bioscience and Space Biotechnology, School of Life Sciences, Northwestern Polytechnical University, Xi'an, Shaanxi 710072, P.R. China

Received August 15, 2015; Accepted August 12, 2016

DOI: $10.3892 / \mathrm{ol} .2017 .5642$

\begin{abstract}
Human aspartyl-(asparaginyl)- $\beta$-hydroxylase (HAAH) has recently been the subject of several studies, as it was previously observed to be overexpressed in numerous types of carcinoma cells and tissues in patient tumor samples. HAAH has been implicated in tumor invasion and metastasis, indicating that it may be an important target and biomarker for tumor diagnosis and treatment. However, the immunological tools currently available for the study of this protein, including monoclonal antibodies, are limited, as is the present knowledge regarding the role of HAAH in tumor therapy and diagnosis. In the present study, a recombinant C-terminal domain of HAAH was expressed in Pichia pastoris and a novel monoclonal antibody (mAb) targeting HAAH (HAAH-C) was constructed. Immunofluorescence and antibody-dependent cellular cytotoxicity (ADCC) assays were used to demonstrate the specificity and ADCC activity of this antibody. The results demonstrated that this anti-C-terminal HAAH mAB, in combination with an existing anti-N terminal $\mathrm{HAAH} \mathrm{mAb}$, exhibited a high response to native $\mathrm{HAAH}$ from carcinoma cell culture supernatant, as measured with a double antibody sandwich enzyme-linked immunosorbent assay. This validated novel mAB-HAAH-C may prompt further studies into the underlying mechanisms of $\mathrm{HAAH}$, and the exploration of its potential in tumor diagnosis and therapy.
\end{abstract}

Correspondence to: Dr Ting Huyan, Key Laboratory for Space Bioscience and Space Biotechnology, School of Life Sciences, Northwestern Polytechnical University, 127 Youyi Xilu, Xi'an, Shaanxi 710072, P.R. China

E-mail: huyanting@nwpu.edu.cn

*Contributed equally

Key words: human aspartyl-(asparaginyl)- $\beta$-hydroxylase, expression, monoclonal antibody, antibody-dependent cellular cytotoxicity assay, sandwich enzyme-linked immunosorbent assay

\section{Introduction}

Human aspartyl-(asparaginyl) $\beta$-hydroxylase (HAAH) is a highly conserved enzyme belonging to the $\alpha$-ketoglutarate-dependent dioxygenase family. HAAH catalyzes the $\beta$-hydroxylation of aspartyl and asparaginyl residues in epidermal growth factor (EGF)-like repeats of certain proteins including Notch, Jagged and Delta-like $(1,2)$. HAAH is highly specific for malignant neoplasms, including hepatocellular carcinoma, lung, pancreatic, colorectal and neural carcinomas (3-5); however, HAAH exhibits minimal expression in normal tissues $(6,7)$. HAAH can be detected in the sera of patients with breast, colon, lung and prostate cancers, and has been developed into early diagnostic kits, such as the Panacea HAAH blood tests (BC Detect ${ }^{\circledR}$ CC Detect $^{\circledR}$, LC Detect ${ }^{\circledR}$ and PC Detect ${ }^{\circledR}$; Panacea Global, Inc., Richmond Hill, ON, Canada; http://www.panaceaglobalinc. com/panacea-haah-blood-test.html).

HAAH may have a potential role in inducing cellular transformation and increasing cell motility and invasiveness, which is required for tumor cell infiltration and metastasis $(3,6)$. The potential in the application of this tumor-associated antigen as a biomarker for tumor diagnosis and treatment has been the subject of several recent investigations (8-10).

HAAH is a type 2 transmembrane protein which can be divided into four distinct domains: A cytoplasmic amino-terminal domain, a transmembrane domain, a negatively charged domain that projects into the lumen of the endoplasmic reticulum and a catalytic carboxyl terminal domain containing dibasic glycine and His 2 motifs; these have all been previously demonstrated to be critical for the aspartyl hydroxylase catalytic activity (2,7). In our previous study, the $\mathrm{N}$-terminal domain of HAAH (HAAH-N), which is responsible for its biological activity, was successfully expressed in Escherichia coli (E. coli), and a monoclonal antibody (mAb) against HAAH-N was obtained (11). Subsequently, this N-terminal specific mAb was applied in the detection of HAAH overexpression and distribution in tumor tissues and cells (8), and exhibited positive specificity and sensitivity to HAAH and its isoform. However, as a potential target and biomarker for tumor diagnosis, the molecular function of HAAH in tumor invasion and metastasis requires further study to be fully understood, and 
to develop more potent and efficient immunological tools. The present study primarily described a method for the expression and purification of the C-terminal domain of HAAH, using the Pichia pastoris expression system in a 10-L bioreactor. In addition, this recombinant protein was used as an immunogen to prepare an mAb against the HAAH C-terminal (HAAH-C). Immunofluorescence was used to demonstrate the specificity of this novel antibody. The antibody-dependent cellular cytotoxicity (ADCC) of natural killer (NK) cells on this antibody was also assessed. Finally, the novel HAAH-C antibody was used to establish a double antibody sandwich enzyme-linked immunosorbent assay (ELISA) method with the previously obtained HAAH-N antibody, and to analysis the HAAH content in the culture supernatant of carcinoma cell lines.

\section{Materials and methods}

Expression and purification of recombinant $H A A H-C$ ( $r H A A C-C)$. HAAH cDNA was obtained using an oligo dT primer (GenScript, Nanjing, China) as described in a previous study $(8,11,12)$. A Pichia expression kit containing the P. pastoris strain GS115 (American Type Culture Collection, Manassas, VA, USA) and the Invitrogen $p P I C 9 k$ vector (Thermo Fisher Scientific, Inc., Waltham, MA, USA) were used to clone the HAAH-C gene. Oligonucleotide primers, including HAAH-C-F, which contained an EcoRI restric-

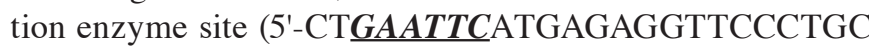
AGA-3') and HAAH-C-R, which contained a NotI restriction

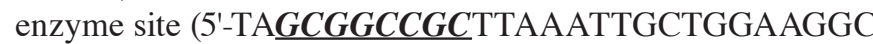
TGCG-3'), were designed using prior published sequences from GenBank (GI:14589865) and used for the amplification of a truncated HAAH gene (969 bp), which encoded a $38 \mathrm{kDa}$ truncated protein. The rHAAH-C was expressed in the $P$. pastoris expression system and induced with methanol in a 10-L Biostat B plus bioreactor (Sartorius AG, Göttingen, Germany). The rHAAH-C in the culture supernatant was purified using the Labscale TFF System (EMD Millipore, Billerica, MA, USA), Sephadex G25 gel-filtration column and DEAE Sepharose FF column (GE Healthcare Bio-Sciences, Pittsburgh, PA, USA), following the manufacturer's instructions.

For SDS-PAGE analysis, the proteins in the culture supernatants were mixed with $2 \mathrm{X}$ loading buffer ( $\mathrm{pH}$ 6.8) containing $1 \mathrm{M}$ Tris, $20 \%$ glycerol, $10 \%$ SDS, $0.1 \%$ bromophenol blue and $5 \% \quad \beta$-mercaptoethanol. A low molecular weight range ladder (Takara Bio, Inc., Otsu, Japan) was used as a standard to evaluate the protein molecular masses. Electrophoresis was carried out on a $12 \%$ polyacrylamide gel under denaturing conditions for $\sim 90$ min with a constant voltage of $120 \mathrm{~V}$. The protein bands were visualized with Coomassie brilliant blue R-250 staining.

For the western blot analysis, the fractionated proteins were transferred onto nitrocellulose membranes (Bio-Rad Laboratories, Inc., Hercules, CA, USA) by electroblotting and probed with a diluted $(1: 1,000)$ anti-HAAH polyclonal antibody (\#CSB-PA002226GA01HU; CUSABIO, Wuhan, China) at $37^{\circ} \mathrm{C}$ for $1 \mathrm{~h}$. This was followed by incubation with a goat anti-rabbit immunoglobulin $(\mathrm{Ig}) \mathrm{G} /$ horseradish peroxidase (HRP; dilution, 1:2,000; Caltag Laboratories, Caltag Medsystems, Buckingham, UK) as the secondary antibody.
The western blots were blocked, washed, and probed at room temperature in $10 \mathrm{mM}$ sodium phosphate ( $\mathrm{pH} 7.4)$, containing $150 \mathrm{mM} \mathrm{NaCl}, 0.1 \%$ bovine serum albumin (BSA) (Gibco; Thermo Fisher Scientific, Inc.) and $0.1 \%$ Tween 20. The detection of rHAAH-C was performed using the Enhanced Chemiluminescence Western Blotting Substrate kit (Pierce; Thermo Fisher Scientific, Inc.).

Generation, purification and characterization of a $m A b$ against $\mathrm{rHAAH}-\mathrm{C}$. The desalted and lyophilized $\mathrm{rHAAH}-\mathrm{C}$ protein was purified using a DEAE Sepharose FF column and weighted and diluted with phosphate buffered saline (PBS) to a concentration of $1 \mathrm{mg} / \mathrm{ml}$; this was subsequently used as an immunogen. For the initial immunization, five female BALB/c mice (age, 6-7 weeks; weight, 22-25 g) were obtained from the Laboratory Animal Center of The Fourth Military Medical University (Xi'an, China) and housed in a specific pathogen-free environment. The mice were subcutaneously vaccinated with $100 \mu \mathrm{g}$ of the immunogen, which was emulsified with an equal volume of complete Freund's adjuvant (Sigma-Aldrich, St. Louis, MO, USA). Subsequent booster injections were administered intraperitoneally, with the same quantity of immunogen, at two and four weeks post initial injection. The antiserum of each mouse was collected from the retrobulbar plexus and indirect ELISA determined each antiserum titer. The best-performing mouse was selected for hybridoma production and boosted with $100 \mu \mathrm{g}$ of the immunogen two days prior to cell fusion.

Mouse myeloma $\mathrm{Sp} 2 / 0$ cells were prepared to a concentration of $4 \times 10^{5}$ cells $/ \mathrm{ml}$ (exponential growth phase) prior to cell fusion. The harvested spleen cells from the immunized mice were combined with $\mathrm{Sp} 2 / 0$ cells at a ratio of $10: 1$ and centrifuged at $300 \times \mathrm{g}$ for $8 \mathrm{~min}$ at room temperature. The pellet was then washed twice and centrifuged again at $300 \mathrm{xg}$ for $8 \mathrm{~min}$ at room temperature. The chamber of a Micro-Pulser Electroporator (Bio-Rad Laboratories, Inc.) was filled with the mixed cells and fusion was conducted immediately. The electro-fusion mode was as follows: Pre-alignment voltage, $5 \mathrm{~V}$ (duration, $30 \mathrm{sec}$ ); pulse voltage, 20-30 V (duration, $15 \mathrm{msec}$ ); and post-alignment voltage, $5 \mathrm{~V}$ (duration, $30 \mathrm{sec}$ ). Following fusion, the chambers were allowed to stand for $10 \mathrm{~min}$ at room temperature. The chamber was unscrewed and the electrode core rinsed with $1 \mathrm{ml}$ of post-fusion medium (RPMI-1640 culture medium supplemented with $10 \%$ fetal calf serum, $10 \mathrm{mM}$ nonessential amino acids, $100 \mathrm{IU} / \mathrm{ml}$ of penicillin and $100 \mu \mathrm{g} / \mathrm{ml}$ of streptomycin) in the electrode beaker. The hybridomas were selectively cultured for approximately two weeks, and an indirect ELISA screened the resulting culture supernatants. The hybridomas that produced antibodies with a good reactivity against $\mathrm{HAAH}-\mathrm{C}$ were subsequently cloned twice more by limiting dilution, followed by expansion for the large-scale production of the $\mathrm{mAb}$.

Following the injection of the hybridoma cells $\left(5 \times 10^{5}\right)$, ascites was observed in BALB/c mice from 7-14 days. The fluids were purified using a Protein $G$ Sepharose 4 Fast Flow column (GE Healthcare Bio-Sciences), and the purity was analyzed by SDS-PAGE, as aforementioned. Isotyping of the mAbs against HAAH-C was determined using a gel gold test strip mouse $\mathrm{mAb}$ isotyping kit (Pierce; Thermo Fisher Scientific, Inc.) following the manufacturer's recommendations. 
Cells. The cell lines of human cervical cancer (HeLa), breast carcinoma (MCF-7), liver hepatocellular carcinoma (HepG2) and mouse myeloma cells lines (Sp2/0) were purchased from the American Type Culture Collection. The cells were maintained in Dulbecco's modified Eagle's medium (DMEM) or RPMI-1640 culture medium (Gibco; Thermo Fisher Scientific, Inc.) supplemented with $10 \%$ fetal calf serum (Gibco; Thermo Fisher Scientific, Inc.) that had been heat-inactivated at $56^{\circ} \mathrm{C}$ for $30 \mathrm{~min}, 10 \mathrm{mM}$ nonessential amino acids, $100 \mathrm{IU} / \mathrm{ml}$ of penicillin and $100 \mu \mathrm{g} / \mathrm{ml}$ of streptomycin (Genview, Carlsbad, CA, USA), in a humidified $5 \% \mathrm{CO}_{2}$ atmosphere at $37^{\circ} \mathrm{C}$.

Human NK cells were expanded and cultured as described previously (13). Briefly, peripheral venous blood $(10 \mathrm{ml})$ from healthy donors $(n=10 ; 3$ females and 7 males; date, 14th March, 2014; Hospital of Northwestern Polytechnical University, Xi'an, China) was collected in heparinized tubes. The procedure of the blood sample collection conformed to the informed consent guidelines of the Ethics Committee of Northwestern Polytechnical University. The peripheral blood mononuclear cells (PBMCs) were collected using Lymphocyte Separation Liquid (Haoyang TBD, Tianjin, China). Following two washes with PBS the PBMCs were resuspended in RPMI-1640 media, which was supplemented with $10 \%$ fetal bovine serum (Gibco; Thermo Fisher Scientific, Inc.) containing 100 IU of interleukin-2 (Peprotech, Inc., Rocky Hill, NJ, USA), $100 \mu \mathrm{g} / \mathrm{ml}$ of penicillin and $100 \mu \mathrm{g} / \mathrm{ml}$ of streptomycin (Genview, Carlsbad, CA, USA). The PBMCs were counted and cocultured with stimulating cells (13). The CD56-PE and CD3-FITC mAbs, and their isotype-matched controls (IgG1-FITC/IgG2-PE; QuantoBio Biotechnology Co., Ltd., Beijing, China), were used to test the percentage of $\mathrm{NK}$ cells $\left(\mathrm{CD} 56^{+} \mathrm{CD}^{-}\right)$in the PBMC suspensions after three weeks of ex vivo-expansion, using flow cytometry (BD FACSCalibur; BD Biosciences, San Jose, CA, USA).

Immunofluorescence cell staining. Hybridoma cells $\left(4 \times 10^{5}\right)$ in $3 \mathrm{ml}$ culture medium were seeded into 6 -well cell culture plates and incubated overnight at $37^{\circ} \mathrm{C}$. After washing three times with ice-cold PBS, the cells were permeabilized for 30 min with $2 \%$ Triton $\mathrm{X}-100$ at room temperature and then blocked with $3 \% \mathrm{BSA}$ at $37^{\circ} \mathrm{C}$ for $30 \mathrm{~min}$. The mAb against HAAH-C (dilution, $1: 100 ; 100 \mu \mathrm{g} / \mathrm{ml}$ ) was applied for $1 \mathrm{~h}$ at $37^{\circ} \mathrm{C}$, followed by a PBS wash for $3 \mathrm{~min}$. The cells were incubated with fluorescein isothiocyanate (FITC)-conjugated goat anti-mouse IgG (\#sc-2010; Santa Cruz Biotechnology, Inc., Dallas, Texas, USA; dilution, 1:200) and propidium iodide (PI) at $37^{\circ} \mathrm{C}$ for $1 \mathrm{~h}$ in the dark. After washing with PBS, the cells were placed with a $50 \%$ glycerol/PBS mounting medium. Images were immediately observed and captured using fluorescent microscopy.

ADCC assay. The ADCC activity of human NK cells on the HAAH-C mAb was measured by calculating the rates at which NK cells killed target cells in a 96-well plate. NK cells were expanded and cultured as previously described $(10,13)$. The target cells (HeLa, MCF-7 and HepG2) were incubated with NK cells as an effector, to a target ratio of 10:1 in the presence or absence of the anti-HAAH-C mAb $(1 \mu \mathrm{g} / \mathrm{ml})$. NK cells $\left(100 \mu \mathrm{l} ; 2 \times 10^{5}\right.$ cells $)$ were plated into each well of a 96-well plate and mixed with $100 \mu 1$ of the target cells $\left(2 \times 10^{4}\right)$. Each experiment was performed in triplicate. The NK cell effector control wells contained $100 \mu \mathrm{l}$ NK cells $\left(2 \times 10^{5}\right)$ and $100 \mu$ RPMI-1640 medium. The target cell control wells contained $100 \mu \mathrm{l}$ target cells $\left(2 \times 10^{4}\right)$ and $100 \mu \mathrm{l}$ RPMI-1640 medium. The plate was incubated at $37^{\circ} \mathrm{C}$ for $4 \mathrm{~h}$ in a $5 \% \mathrm{CO}_{2}$ atmosphere; subsequently, $20 \mu \mathrm{l}$ Cell Counting Kit-8 (Dojindo Molecular Technologies, Inc., Shanghai, China) was added to each well and the plate was then incubated for another $2 \mathrm{~h}$. The absorbance $(A)$ values were recorded at $450 \mathrm{~nm}$, and the killing rate of NK cells compared with the target cells was calculated with the following equation (14):

$$
\text { Killing rate }(\%)=\left[1-\left(A_{\mathrm{e}+\mathrm{t}}-A_{\mathrm{e}}\right) / A_{\mathrm{t}}\right] \times 100 \%
$$

In this equation, $A_{\mathrm{e}}$ is the mean $A_{450}$ of triplicate wells for the NK cell control; $A_{t}$, is the mean $A_{450}$ of triplicate wells for the target cell control; and $A_{\mathrm{e}+\mathrm{t}}$ is the mean $A_{450}$ of triplicate wells for NK cells plus target cells.

Double antibody sandwich-ELISA. The anti-HAAH-C $\mathrm{mAb}$ was used as capture antibody, whereas anti-HAAH-N $\mathrm{mAb}$ was used as detection antibody in the double antibody sandwich-ELISA. The culture supernatant of three tumor cells lines (HeLa, MCF-7, HepG2) and NK cells (negative control) were used as test samples. The dilution of the capture antibody, detection antibody, test samples and goat anti-mouse IgG-HRP conjugate (\#ab97023; Abcam, Shanghai, China) were optimized by checkerboard titration. Sandwich ELISA was performed following the method described in literature (15). Anti-HAAH-C mAb was diluted in a coating buffer (0.05 M carbonate-bicarbonate buffer, $\mathrm{pH}$ 9.6) and coated microtiter plates at $4^{\circ} \mathrm{C}$ overnight. After washing three times with PBS containing $0.05 \%$ (v/v) Tween-20 (PBST), the wells were blocked with $5 \% \mathrm{BSA}(\mathrm{pH} 7.2)$ at room temperature for $2 \mathrm{~h}$. Subsequently, the plates were incubated at $37^{\circ} \mathrm{C}$ for $1 \mathrm{~h}$ with $100 \mu \mathrm{l}$ of diluted samples. After washing six times with PBST, anti-HAAH-N mAb was added into each well to detect the antigens (HAAH in culture supernatant). The wells were washed again with PBST to remove unbound antibodies, and then the plates were incubated with HRP-conjugated goat anti-mouse $\operatorname{IgG}$ antibody diluted in diluent buffer at $37^{\circ} \mathrm{C}$ for $1 \mathrm{~h}$. The bound-antibodies were detected by dispensing a TMB HRP Color Development Solution (Beyotime Institute of Biotechnology, Shanghai, China). Finally the absorbance was measured at $450 \mathrm{~nm}$ in microplate reader (BioTek Synergy-4). rHAAH protein (Cusabio, Wuhan, China) at various concentrations $(400,200,100,50,25,12.50,6.25,3.13,1.56$, and $0 \mathrm{ng} / \mathrm{ml}$ ) in diluent buffer was used to generate a standard curve for evaluating test samples quantitatively. The cut-off value was defined as the mean value plus three standard deviations (SD) of the mean $A$ value obtained from RPMI-1640 culture medium (negative control).

Statistical analysis. Statistical analysis was performed using SPSS 16.0 statistical software (SPSS, Inc., Chicago, IL USA). The data are presented as the mean \pm standard deviation. The results were analyzed using the analysis of variance. Multiple comparisons used a least significant difference test to evaluate the significance of differences between groups. $\mathrm{P}<0.05$ was considered to indicate a statistically significant result. 


\section{Results}

Expression and purification of $r H A A H-C$. The high-level expression of HAAH-C by fermentation was terminated at $118 \mathrm{~h}$, with a cell wet-weight of $521 \mathrm{~g} / \mathrm{l}$ in the $10-\mathrm{L}$ bioreactor. It was revealed that the highest expression of 38-kDa rHAAH-C was at $96 \mathrm{~h}$ post methanol induction (Fig. 1A). Analysis of the western blot indicated that the $\mathrm{HHAAH}-\mathrm{C}$ protein reacted markedly with the polyclonal antibody against HAAH and exhibited a high specificity (Fig. 1B).

All the purification steps were monitored through SDS-PAGE. The cell-free supernatant was concentrated by ultrafiltration and purified on a Sephadex G25 gel-filtration column. Fractions of certain protein impurities were pooled, concentrated and purified using a DEAE Sepharose FF column (Fig. 1C). The purification procedure resulted in the recovery of $92.4 \mathrm{mg}$ of rHAAH-C from the culture supernatant, accounting for $\sim 53.8 \%$ of the total protein content (Table I).

Generation, purification and characterization of an $m A b$ against $r H A A H-C$. Following the initial injection and three subsequent boosters, the maximum titer of the anti-HAAH-C $\mathrm{mAb}$ purified from the sera of the immunized mice was approximately $5 \times 10^{3}$, as determined by an indirect ELISA (data not shown). The highest reacting mouse was given a fourth booster and selected for hybridoma fusion, which increased the titer to $1 \times 10^{4}$ (data not shown). The fusion cells were seeded in a 96-well culture plate. Following a two-week culture, the hybridoma cell clones formed in 85 of the plate wells, yielding a fusion ratio of $88.5 \%$. Seven of the hybridoma clones in the aforementioned 85 wells were selected on the basis of their notable ELISA reactivities with the HAAH-C protein and subsequently subjected to cloning procedures. Four of these clones (A3, A6, C9, and E4), which exhibited the best titers, affinities, and cell growth, were finally selected for limiting dilution.

Purification of the ascites fluid was performed using a Protein G Sepharose 4 Fast Flow column to 95\% homogeneity, as assessed by SDS-PAGE (Fig. 2A). An indirect ELISA of the ascites fluid indicated that the titers of the mAbs specific against rHAAH-C ranged from $5 \times 10^{3}$ to $1.5 \times 10^{4}$. These mAbs were able to specifically react with $\mathrm{rHAAH}-\mathrm{C}$ as determined by the western blot analysis (Fig. 2B). A mouse mAb isotyping test kit determined that the Ig subclasses of the mAbs secreted

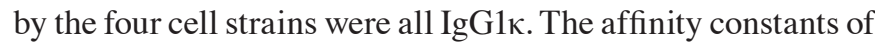
the four mAbs ranged from $1.7 \times 10^{8}$ to $1.2 \times 10^{9}$, as determined by a noncompetitive ELISA (Table II).

Immunofluorescence staining in carcinoma cell lines. To identify the specificity of the mAbs against HAAH-C, the HAAH protein expression levels in each of the three carcinoma cell lines (HeLa, MCF-7 and HepG2) were evaluated by immunofluorescence, using the aforementioned $\mathrm{C} 9 \mathrm{mAb}$. As indicated in Fig. 3, the anti-HAAH-C mAb exhibited high affinity in the three carcinoma cell lines. HAAH expression on the cytomembrane of HepG2 cells was higher than in the other cell lines; similarly, HAAH expression in HeLa cells was greater than in MCF-7. As the negative control, human primary NK cells were observed to have no reaction to the $\mathrm{mAb}$.
Table I. Purification of recombinant human aspartyl(asparaginyl) $\beta$-hydroxylase C-terminal.

\begin{tabular}{lcr}
\hline Fraction & $\begin{array}{r}\text { Protein } \\
(\mathrm{mg} / \mathrm{l})\end{array}$ & $\begin{array}{c}\text { Yield } \\
(\%)\end{array}$ \\
\hline Cell-free supernatant & 225.8 & 100 \\
Ultrafiltration & 181.9 & 80.6 \\
DEAE Sepharose FF column & 127.1 & 56.2 \\
Sephadex G25 gel-filtration column & 92.4 & 40.9 \\
\hline
\end{tabular}

Table II. Identification and characterization of anti-human aspartyl-(asparaginyl) $\beta$-hydroxylase C-terminal monoclonal antibodies.

\begin{tabular}{lcccc}
\hline Hybridoma & $\begin{array}{c}\text { Class } \\
\text { and } \\
\text { subclass }\end{array}$ & Type & $\begin{array}{c}\text { Titer of } \\
\text { supernatant } \\
\text { of ascites }\end{array}$ & $\begin{array}{c}\text { Affinity } \\
\text { constant } \\
\left(\mathrm{M}^{-1}\right)\end{array}$ \\
\hline $\mathrm{A} 3$ & $\mathrm{IgG}_{1}$ & $\kappa$ & $1: 5,000$ & $1.7 \times 10^{8}$ \\
$\mathrm{~A} 6$ & $\mathrm{IgG}_{1}$ & $\kappa$ & $1: 10,000$ & $4.6 \times 10^{8}$ \\
$\mathrm{C} 9$ & $\mathrm{IgG}_{1}$ & $\kappa$ & $1: 15,000$ & $1.2 \times 10^{9}$ \\
$\mathrm{E} 4$ & $\mathrm{IgG}_{1}$ & $\kappa$ & $1: 10,000$ & $2.2 \times 10^{8}$ \\
\hline
\end{tabular}

NK cell-mediated ADCC. Primary human NK cells were harvested following 21 days of ex vivo expansion. The percentage of $\mathrm{NK}$ cells $\left(\mathrm{CD}^{+} 6^{+} \mathrm{CD} 3^{-}\right)$within the PBMCs was determined by flow cytometry, using staining with the CD56-PE and CD3-FITC mAbs. In one donor sample, the maximal percentage of NK cells following expansion was 93.18\% (Fig. 4A); the mean percentage of NK cells in 10 donor samples was $90.12 \pm 4.23 \%(\mathrm{n}=10)$. With a high specificity, anti-HAAH-C mAb was able to promote NK cells to combine with the target cells and so increase the ADCC (Fig. 4B). The results of the current study demonstrated that, in the presence of $10 \mu \mathrm{g} / \mathrm{ml}$ anti-HAAH-C mAbs, the cytotoxicity of NK cells with regard to HepG2 was markedly increased, enhanced by $16.25 \%(50.66 \pm 3.07 \%$ increased to $66.91 \pm 2.46 \% ; \mathrm{P}=0.018)$. The cytotoxicity rates in HeLa cells and MCF-7 cells were increased by $13.28 \%(36.52 \pm 3.02$ to $49.80 \pm 3.95 \% ; \mathrm{P}=0.024)$ and $6.26 \%(55.45 \pm 2.5$ to $61.7 \pm 2.23 \%$; $\mathrm{P}=0.013)$, respectively. Values are presented as the mean \pm SD of four independent experiments.

HAAH detection in carcinoma cell culture supernatant. By using a double antibody sandwich ELISA, the levels of soluble HAAH in the culture supernatant of the carcinoma cell lines were determined. According to the chessboard reagent titrations, the optimized concentration of the capture antibody was $10 \mu \mathrm{g} / \mathrm{ml}$ in $100 \mu \mathrm{l}$ per well. The dilution of the detection antibody was 1:1,000 (1 ng/ml) and that of the secondary antibody was $1: 250$. Recombinant HAAH was prepared in serial dilutions $(1.56-400 \mathrm{ng} / \mathrm{ml})$ to generate a standard curve. The association between the $A_{450}$ and the HAAH antigen concentration was obtained as demonstrated in the following formula: $\mathrm{y}=0.102 \mathrm{x}+0.2506, \mathrm{R}^{2}=0.9899$; this association 

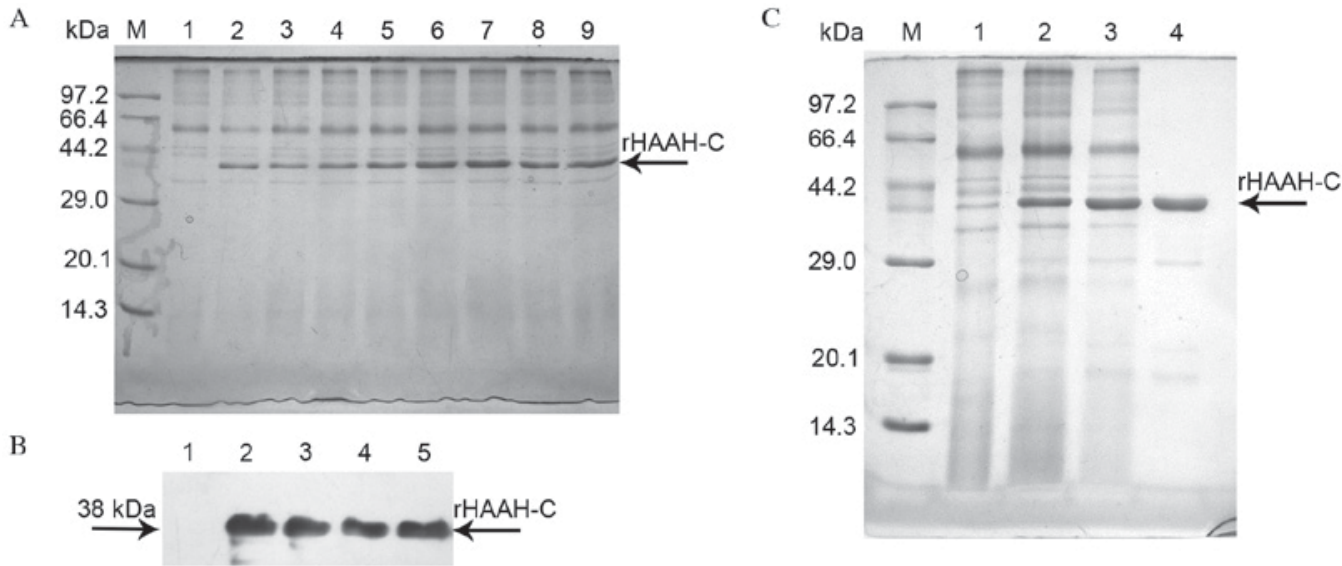

Figure 1. Characterization and purification of rHAAH-C protein. (A) SDS-PAGE analysis of the expression of rHAAH-C in high cell-density fermentation. Lane M, a molecular weight standard; lanes 1-9, rHAAH-C (fermentation times: lane 1, 0 h; lane 2, 12 h; lane 3, 24 h; lane 4, 36 h; lane 5, 48 h; lane 6, 72 h; lane 7,96 h; lane 8, $108 \mathrm{~h}$; lane 9,120 h). The main recombinant protein band is denoted with an arrow. (B) Western blot analysis of the expression of rHAAH-C in high cell-density fermentation. Lane 1, a sample of the whole culture supernatant prior to methanol induction (negative control); lanes 2-5, parallel samples of the whole culture supernatant following methanol induction. The samples were probed with an anti-HAAH polyclonal antibody. (C) SDS-PAGE analysis of the purification of rHAAH-C expressed in P. pastoris. Lane M, a molecular weight standard; lane 1, negative control for the secreted protein; lane 2, crude secreted protein; lane 3, protein purified using Sephadex G25 gel-filtration chromatography; lane 4, protein purified using DEAE ion-exchange chromatography. HAAH, human aspartyl-(asparaginyl)- $\beta$-hydroxylase; SDS-PAGE, sodium dodecyl sulfate polyacrylamide gel electrophoresis; rHAAC-C, recombinant HAAH C-terminal; P. pastoris, Pichia pastoris.

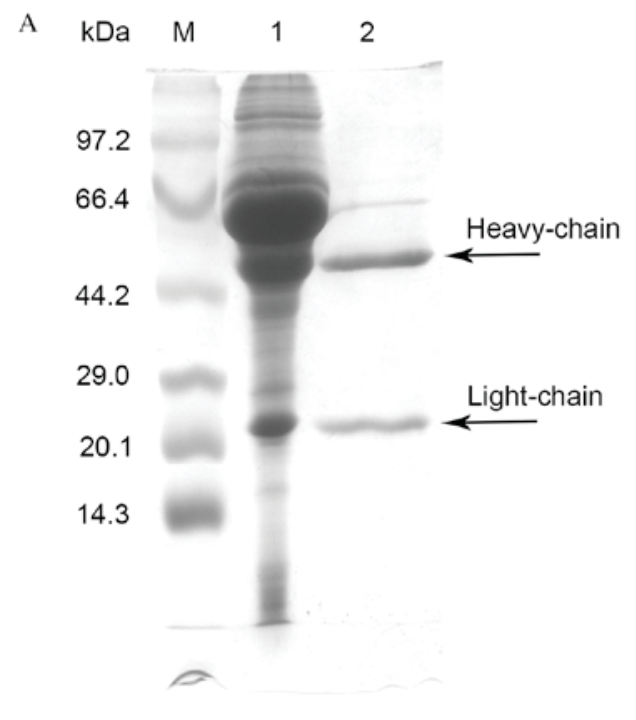

B

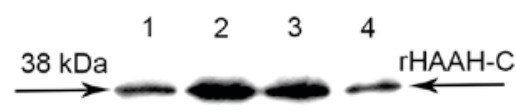

Figure 2. SDS-PAGE and western blot analysis of the purification of the mAbs against rHAAH-C. (A) A time course of the whole culture supernatant. Lane M, a molecular weight standard; lane 1, the ascites fluid; lane 2, the eluate sample of the mAbs against rHAAH-C (heavy chain and light chain); (B) Western blot analysis of the rHAAH-C mAbs. Lane 1, a sample probed with the $\mathrm{mAb}$ A3; lane 2, a sample probed with the $\mathrm{mAb} \mathrm{A6}$; lane 3, a sample probed with the $\mathrm{mAbC}$; lane 4, a sample probed with the mAb E4. HAAH, human aspartyl-(asparaginyl)- $\beta$-hydroxylase; rHAAC-C, recombinant HAAH C-terminal; mAbs, monoclonal antibodies.

exhibited a good linear response in the concentration range of $10-200 \mathrm{ng} / \mathrm{ml}$ (Fig. 5). The cut off value was $2 \mathrm{ng} / \mathrm{ml}$. From this standard curve, the concentrations of soluble HAAH in the carcinoma culture supernatant were determined to be $85 \pm 35 \mathrm{ng} / \mathrm{ml}$ (HeLa), 202 $\pm 47 \mathrm{ng} / \mathrm{ml}(\mathrm{HepG} 2)$ and 47 $\pm 19 \mathrm{ng} / \mathrm{ml}$
(MCF-7). The HAAH protein was not detected in the NK cell supernatant (negative control).

\section{Discussion}

HAAH, a membrane protein with hydroxylation activity, has been observed to be overexpressed in numerous malignant neoplasms and has recently been the subject of several studies $(4-7,14,16)$. A previous study demonstrated that the HAAH gene was frequently overexpressed in a variety of carcinomas in Asian patients, by contrast to its relatively low expression in normal tissues (8). HAAH can also be detected in the sera of patients with breast, ovarian, lung and prostate cancers (3-6). As such, the development of an efficient detection method is critical.

Several hosts, including $E$. coli and various mammalian cell lines, have been used to express the recombinant subtype proteins of HAAH $(2,17)$. A previous investigation also used the pProEX expression system to express humbug (a subtype of HAAH) in E. coli (11). One of the limitations of the expression system in E. coli, was that the formation of inclusion bodies and its refolding purification may reduce the recovery yields (18). To obtain the HAAH-C protein with an improved three-dimensional structure and ability to prepare a mAb, the $P$. pastoris expression system was selected for the current study (19). The procedure for the protein expression and purification involved three steps. Firstly, a eukaryotic $P$. pastoris expression system that was compatible with the insertion of, and selection for, multiple gene copies was selected for the HAAH expression (data not shown). Secondly, high cell-density fermentation in a 10-L bioreactor facilitated the effective production of the recombinant $\mathrm{HAAH}$ protein under controlled induction conditions, including the $\mathrm{pH}$, temperature and dissolved $\mathrm{O}_{2}$ concentration. Finally, a two-step purification procedure was utilized to maintain the functionality and yield of the rHAAH-C. 


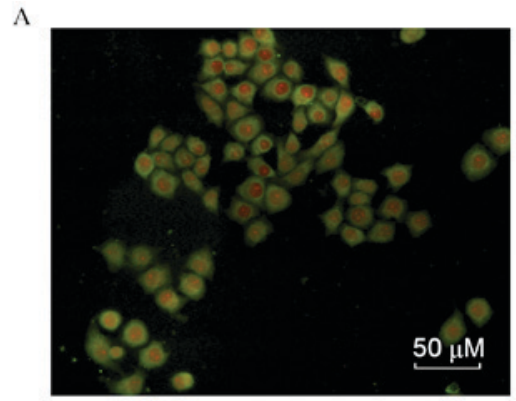

HeLa

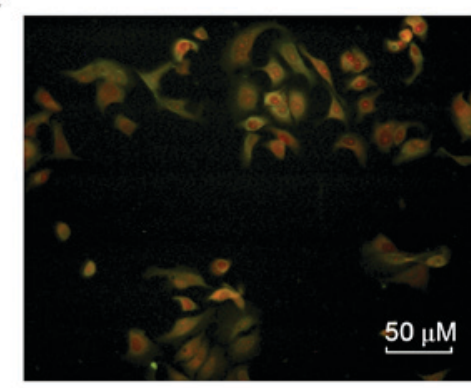

MCF-7
B

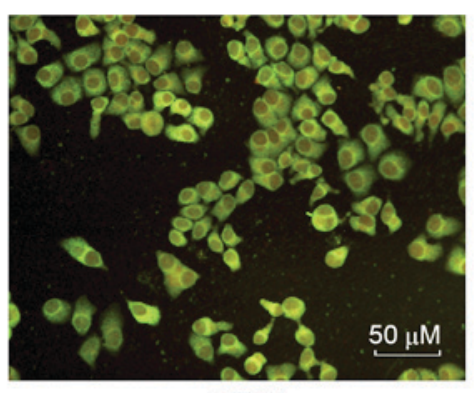

HepG2

D

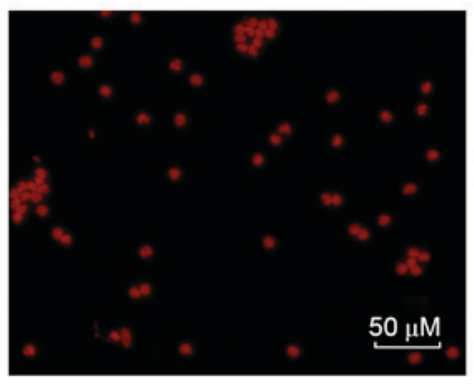

NK

Figure 3. Indirect cellular immunofluorescence detection of the HAAH protein in carcinoma cell lines. (A) HeLa; (B) HepG2; (C) MCF-7; (D) NK cells. The cells were incubated with the mAb against HAAH-C at a dilution of 1:100 $(100 \mu \mathrm{g} / \mathrm{ml})$ and then probed with the fluorescein isothiocyanate-conjugated goat anti-mouse immunoglobulin $\mathrm{G}$ antibody (dilution, 1:200) and propidium iodide. Images were immediately observed and captured using fluorescence microscopy. HAAH, human aspartyl-(asparaginyl)- $\beta$-hydroxylase; rHAAC-C, recombinant HAAH C-terminal; mAbs, monoclonal antibodies; NK, natural killer.
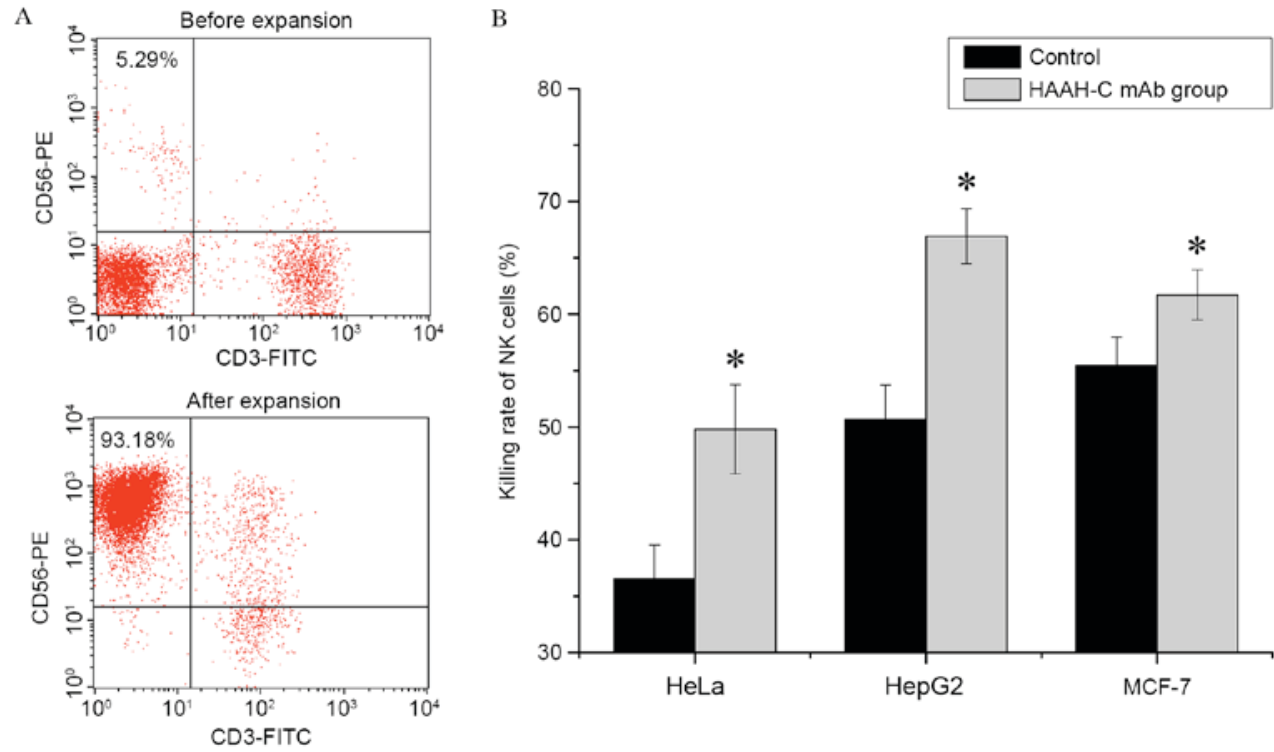

Figure 4. NK cell expansion in vitro and ADCC induced by HAAH-C mAb treatment in vitro. (A) PBMCs were co-cultured with stimulating cells and harvested following a 21-day ex vivo expansion. All pellets were stained with CD56-PE and CD3-FITC mAbs and analyzed by flow cytometry. The percentage of $\mathrm{NK}$ cells $\left(\mathrm{CD} 56^{+} \mathrm{CD} 3\right)$ in the PBMC population was determined. PBMCs were analyzed by flow cytometry before and after expansion. The percentage of NK cells $\left(\mathrm{CD}^{+} 6^{+} \mathrm{CD} 3\right)$ in the PBMCs was $\sim 5.29 \%$ before expansion and $\sim 93.18 \%$ after expansion. (B) In the ADCC assay, HeLa, HepG2 and MCF-7 tumor cells were mixed with NK cells at ratio of $10: 1$ in the presence or absence of the HAAH-C mAb $(1 \mu \mathrm{g} / \mathrm{ml})$. Following a $4-\mathrm{h}$ incubation at $37^{\circ} \mathrm{C}$, cell samples were stained with Cell Counting Kit- 8 and the killing rate of the NK cells was analyzed by a multiscan spectrum. Values are presented as the means $( \pm$ standard deviation) of four independent experiments, ${ }^{*} \mathrm{P}<0.05$ vs. the control. HAAH, human aspartyl-(asparaginyl)- $\beta$-hydroxylase; rHAAH-C, recombinant HAAH C-terminal; P. pastoris, Pichia pastoris; mAbs, monoclonal antibodies; NK, natural killer; FITC, fluorescein isothiocyanate; PE, phycoerythrin; ADCC, antibody-dependent cellular cytotoxicity; PBMCs, peripheral blood mononuclear cells.

In a previous study, the recombinant humbug had been expressed in E. coli and a mAb against humbug (containing the HAAH-N terminal) was obtained by co-immunizing mice (8). In the present study, the rHAAH C protein was expressed using the $P$. pastoris expression system and the $\mathrm{mAb}$ against this recombinant protein was obtained. Compared with a previous $\mathrm{mAb}(11)$, this novel anti-HAAH-C $\mathrm{mAb}$ had improved activity (a titer of $1.5 \times 10^{4}$ compared with 


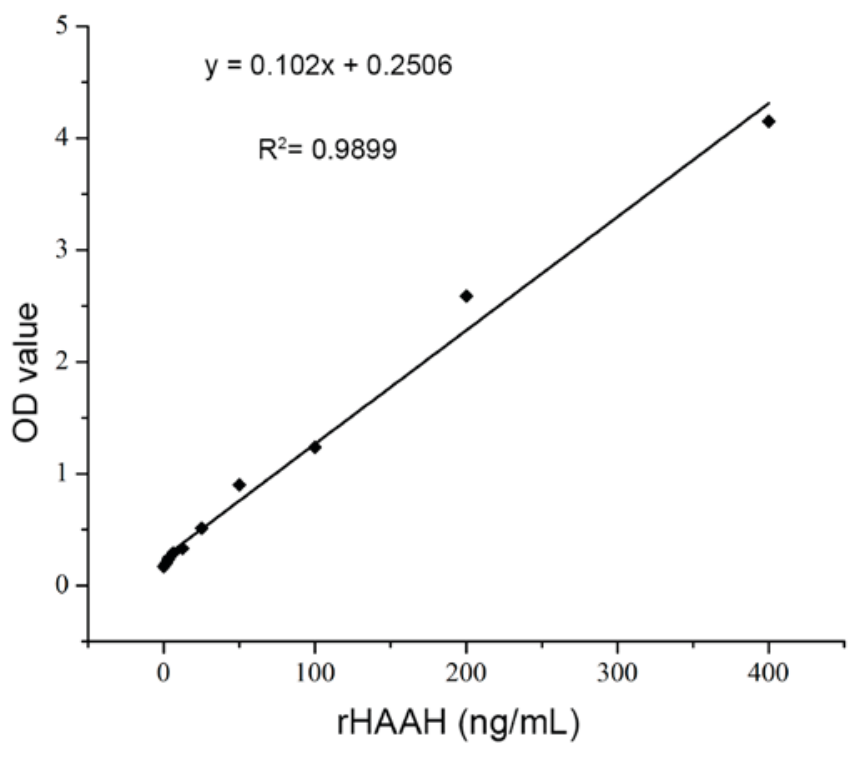

Figure 5. Generation of a standard curve based on serially diluted rHAAH added in a double antibody sandwich enzyme-linked immunosorbent assay. Standard rHAAH protein $(1.56-400 \mathrm{ng} / \mathrm{ml})$ in a diluent buffer was used to generate a standard curve for the quantitative evaluation of the test samples. The cut-off value was defined as the mean \pm three standard deviations of the mean OD value obtained from the RPMI-1640 culture medium (negative control). HAAH, human aspartyl-(asparaginyl)- $\beta$-hydroxylase; rHAAC, recombinant HAAH; OD, optical density.

$1 \times 10^{4}$ for the anti-HAAH-N mAb) and was able to combine with the HAAH expressed on tumor cell membranes. Immunofluorescent cell staining results indicated that, compared with the low or absent expression in the primary NK cells, HAAH was overexpressed in the HeLa, MCF-7 and HepG2 carcinoma cell lines and its distribution pattern was primarily cytoplasmic, with perinuclear and plasmalemmal accentuation.

As an activating low-affinity receptor, CD16 (FcgRIIIa) is able to recognize the fragment crystallizable region of IgG-isotype antibodies. The majority of NK cells express CD16, through which they recognize and target IgG-coated cells, in a process termed ADCC (20). It has been previously reported that IgG1 antibodies are more ADCC-efficient than IgG2 antibodies $(21,22)$. In the present study, the prepared HAAH-C mAb was an IgG1-isotype; the ADCC of NK cells was assayed. The results of the present study revealed that the HAAH-C mAb increased the ADCC of the NK cells on HeLa, MCF-7 and HepG2 cells. Among them, the cytotoxicity of NK cells on HepG2 exhibited a significant increase. This may have been associated with HepG2 expressing the most HAAH on its cell membrane.

Carcinoma immunotherapy and chimeric antigen receptor NK cell immunotherapy has been the subject of numerous studies in recent years $(12,21,23)$. The cytotoxicity of NK cells on tumor cells has been utilized to treat various types of cancer, including breast, ovarian, lung and prostate, without the adverse effects of radiotherapy or chemotherapy. The characteristics of the novel anti-HAAH-C mAb, with increased NK cell ADCC activity, indicate its potential applications in immunotherapy for liver carcinomas, in addition to other types of tumors. Furthermore, coupled with the exclusivity of the surface expression of HAAH on tumor cells, the high affinity of the anti-HAAH-C mAb for HAAH indicates that it may be developed as a vehicle for the specific delivery of cytotoxic agents to certain types of tumor cells and tissues.

In the present study, a double antibody sandwich-ELISA has been demonstrated to be a promising diagnostic tool for the detection of the circulating HAAH antigen in the sera of cancer patients. Thus far, the available commercial ELISA kits for the detection of HAAH were developed based on a polyclonal antibody strategy. In the present study, by employing the novel prepared anti-HAAH-C $\mathrm{mAb}$ and the existing anti-HAAH-N mAb, the double antibody sandwich-ELISA method was developed to detect the soluble HAAH protein in the culture supernatant of certain carcinoma cell lines. HepG2 cells were observed to secrete the majority of the HAAH in the supernatant, $200 \mathrm{ng} / \mathrm{ml}$, whereas HAAH was barely detectable or undetectable in the supernatant of the NK cells. The cut off value of the preliminary method developed in the present study was $2 \mathrm{ng} / \mathrm{ml}$.

The detection of HAAH levels in the sera of tumor patients remains challenging. A study conducted by Panacea Global Inc. (24-27) indicated that the mean level of HAAH in the sera of patients with lung cancer was $18-22 \mathrm{ng} / \mathrm{ml}$. In the sera of breast, colorectal and prostate cancer patients, this mean level was 15-19, 24-34 and 17.6-34.6 ng/ml, respectively. The ELISA method developed in the present study exhibited a linear association in the concentration range of 10-200 ng/ml, which may be sufficient to facilitate HAAH detection in patient sera. Further studies may examine the HAAH levels in cancer patient sera with a larger number of tissue samples, in order to verify the hypothesis of the present study and improve the discussed detection method.

To the best of our knowledge, this is the first report detailing the preparation of an anti-HAAH-C mAb; the results of the present study indicate that it may be an effective tool to use in further studies of HAAH detection, distribution and function, and that it may be a potential antitumor drug for the immunotherapy of various types of cancer.

\section{Acknowledgements}

The authors acknowledge the financial support from the National Natural Science Foundation of China (grant nos. 31500688, 11472224 and 81502465), the Fundamental Research Funds for the Central Universities [grant nos. 3102015ZY099, 3102015BJ (II)GH09 and 3102016OQD042], and the Basic Research Foundation of Northwestern Polytechnical University (grant no.JC20110286).

\section{References}

1. Dinchuk JE, Focht RJ, Kelley JA, Henderson NL, Zolotarjova NI, Wynn R, Neff NT, Link J, Huber RM, Burn TC, et al: Absence of post-translational aspartyl beta-hydroxylation of epidermal growth factor domains in mice leads to developmental defects and an increased incidence of intestinal neoplasia. J Biol Chem 277: 12970-12977, 2002.

2. Treves S, Feriotto G, Moccagatta L, Gambari R and Zorzato F: Molecular cloning, expression, functional characterization, chromosomal localization and gene structure of junctate, a novel integral calcium binding protein of sarco(endo)plasmic reticulum membrane. J Biol Chem 275: 39555-39568, 2000. 
3. Ince N, de la Monte SM and Wands JR: Overexpression of human aspartyl (asparaginyl) beta-hydroxylase is associated with malignant transformation. Cancer Res 60: 1261-1266, 2000.

4. Maeda T, Taguchi K, Aishima S, Shimada M, Hintz D, Larusso N, Gores G, Tsuneyoshi M, Sugimachi K, Wands JR and de la Monte SM: Clinicopathological correlates of aspartyl (asparaginyl) beta-hydroxylase over-expression in cholangiocarcinoma. Cancer Detect Prev 28: 313-318, 2004

5. Lavaissiere L, Jia S, Nishiyama M, de la Monte S, Stern AM, Wands JR and Friedman PA: Overexpression of human aspartyl(asparaginyl)beta-hydroxylase in hepatocellular carcinoma and cholangiocarcinoma. J Clin Invest 98: 1313-1323, 1996.

6. Sepe PS,Lahousse SA, Gemelli B, Chang H, Maeda T, Wands JR and de la Monte SM: Role of the aspartyl-asparaginyl-beta-hydroxylase gene in neuroblastoma cell motility. Lab Invest 82: 881-891, 2002.

7. Dinchuk JE, Henderson NL, Burn TC, Huber R, Ho SP, Link J, O'Neil KT, Focht RJ, Scully MS, Hollis JM, et al: Aspartyl beta-hydroxylase (Asph) and an evolutionarily conserved isoform of Asph missing the catalytic domain share exons with junctin. J Biol Chem 275: 39543-39554, 2000.

8. Yang H, Song K, Xue T, Xue XP, Huyan T, Wang W and Wang H: The distribution and expression profiles of human Aspartyl/Asparaginyl beta-hydroxylase in tumor cell lines and human tissues. Oncol Rep 24: 1257-1264, 2010.

9. Xue T, Su J, Li H and Xue X: Evaluation of HAAH/humbug quantitative detection in the diagnosis of hepatocellular carcinoma. Oncol Rep 33: 329-337, 2015.

10. Huyan T, Li Q, Ye LJ, Yang H, Xue XP, Zhang MJ, Huang QS Yin DC and Shang P: Inhibition of human natural killer cell functional activity by human aspartyl $\beta$-hydroxylase. Int Immunopharmacol 23: 452-459, 2014.

11. Xue T, Xue XP, Huang QS, Wei L, Sun K and Xue T: Monoclonal antibodies against human aspartyl (asparaginyl) beta-hydroxylase developed by DNA immunization. Hybridoma (Larchmt) 28 251-257, 2009.

12. Sharp PM and Li WH: The codon adaptation index-a measure of directional synonymous codon usage bias, and its potential applications. Nucleic Acids Res 15: 1281-1295, 1987.

13. Li Q, Mei Q, Huyan T, Xie L, Che S, Yang H, Zhang M and Huang Q: Effects of simulated microgravity on primary human NK cells. Astrobiology 13: 703-714, 2013.

14. Xian ZH, Zhang SH, Cong WM, Yan HX, Wang K and Wu MC: Expression of aspartyl beta-hydroxylase and its clinicopathological significance in hepatocellular carcinoma. Mod Pathol 19: 280-286, 2006.

15. Luo Y, Terkawi MA, Jia H, Aboge GO, Goo YK, Cao S, Li Y, $\mathrm{Yu}$ L, Ooka H, Kamyingkird K, et al: A double antibody sandwich enzyme-linked immunosorbent assay for detection of secreted antigen 1 of Babesia microti using hamster model. Exp Parasitol 130: 178-182, 2012
16. Maeda T, Sepe P, Lahousse S, Tamaki S, Enjoji M, Wands JR and de la Monte SM: Antisense oligodeoxynucleotides directed against aspartyl (asparaginyl) beta-hydroxylase suppress migration of cholangiocarcinoma cells. J Hepatol 38: 615-622, 2003.

17. Lee JH: Overexpression of humbug promotes malignant progression in human gastric cancer cells. Oncol Rep 19: 795-800, 2008

18. Baneyx F: Recombinant protein expression in Escherichia coli. Curr Opin Biotechnol 10: 411-421, 1999.

19. Brake AJ, Merryweather JP, Coit DG, Heberlein UA, Masiarz FR, Mullenbach GT, Urdea MS, Valenzuela P and Barr PJ: Alpha-factor-directed synthesis and secretion of mature foreign proteins in Saccharomyces cerevisiae. Proc Natl Acad Sci USA 81: 4642-4646, 1984.

20. Oppenheim DE, Spreafico R, Etuk A, Malone D, Amofah E, Peña-Murillo C, Murray T, McLaughlin L, Choi BS, Allan S, et al: Glyco-engineered anti-EGFR mAb elicits ADCC by NK cells from colorectal cancer patients irrespective of chemotherapy. $\mathrm{Br}$ J Cancer 110: 1221-1227, 2014.

21. Nimmerjahn F and Ravetch JV: Divergent immunoglobulin $\mathrm{g}$ subclass activity through selective Fc receptor binding. Science 310: 1510-1512, 2005.

22. Schneider-Merck T, Lammerts van Bueren JJ, Berger S, Rossen K, van Berkel PH, Derer S, Beyer T, Lohse S, Bleeker WK, Peipp M, et al: Human IgG2 antibodies against epidermal growth factor receptor effectively trigger antibody-dependent cellular cytotoxicity but, by contrast to IgG1, only by cells of myeloid lineage. J Immunol 184: 512-520, 2010.

23. Chen Y, Wang Y, Zhuang Y, Zhou F and Huang L: Mifepristone increases the cytotoxicity of uterine natural killer cells by acting as a glucocorticoid antagonist via ERK activation. PLoS One 7: e36413, 2012

24. Panacea Global: A New and Sensitive Diagnostic Test for the Detection of Breast Cancer-BC Detect. http://www.panaceaglobalinc.com/edit/files/pdfs/bc_detect/35-bcd-pub.pdf.

25. Panacea Global: A New and Sensitive Diagnostic Test for the Detection of Colorectal Cancer-CC Detect. http://www.panaceaglobalinc.com/edit/files/pdfs/cc_detect/36ccd-pub.pdf.

26. Panacea Global: A New and Sensitive Diagnostic Test for the Detection of Lung Cancer-LC Detect. http://www.panaceaglobalinc.com/edit/files/pdfs/lc_detect/37-lcd-pub.pdf.

27. Panacea Global: A New and Sensitive Diagnostic Test for the Detection of Prostate Cancer-PC Detect. http://www.panaceaglobalinc.com/edit/files/pdfs/pc_detect/38-pcd-pub.pdf. 